\title{
Adolescentes Grávidas: Vivências de uma Nova Realidade
}

Pregnant teenagers: Experiences of a new reality

Florinaldo Carreteiro Pantoja Universidade Federal do Amapá

Júlia Sursis

Nobre Ferro Bucher \& Cristiane Holanda Queiroz

Universidade

de Fortaleza 


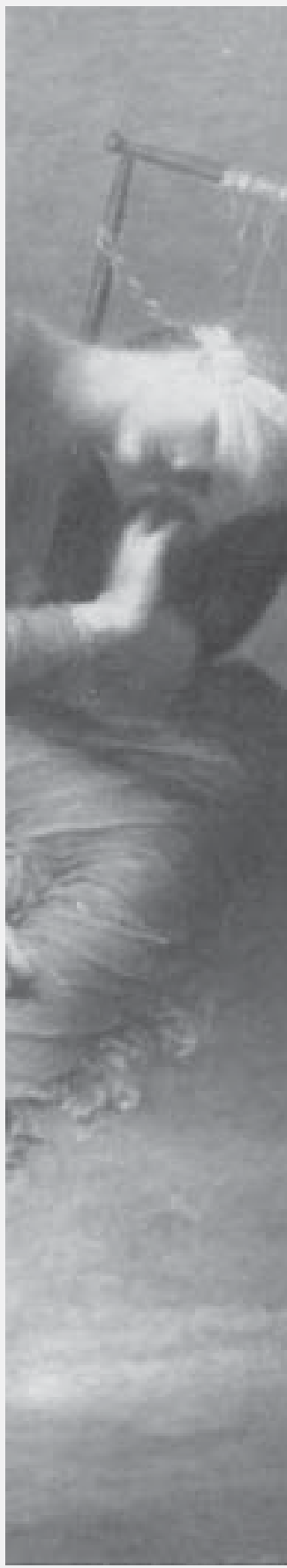

Resumo: O número de adolescentes grávidas vem crescendo anualmente em todo o mundo e vem se tornando uma questão de saúde pública. Em função disso, bem como da carência de pesquisas que abordem as questões subjetivas das vivências de adolescentes grávidas, surgiu a necessidade de se estudar a complexidade desse problema, que afeta as áreas da educação, da saúde e das relações familiares. Para realizar esta pesquisa, optamos por uma abordagem qualitativa, dada a sua capacidade de propiciar melhor interação entre os envolvidos no processo. Os sujeitos escolhidos para o estudo foram dez adolescentes grávidas de baixa renda, com idades entre 16 e 19 anos, que foram atendidas numa unidade básica de saúde na cidade de Macapá, no Estado do Amapá. Os resultados constatam que é preciso aprimorar a educação sexual dentro de uma perspectiva socioeconômica, não apenas nas escolas mas também através da integração com as unidades de saúde pública, e promover espaços mais acolhedores para os adolescentes discutirem sobre sexualidade.

Palavras-chave: adolescência, gravidez, sexualidade e saúde pública.

Abstract: The number of pregnant teenagers is increasing annually in the whole world, becoming an issue of public health. Because of this, as well as for the lack of research about the subjectivity of pregnant teenagers' experiences, it seemed necessary to study the complexity of this problem that affects the areas of education, health and family relationships. To carry through this research, we decided to use a qualitative approach because of its capacity to propitiate better interaction among the people involved in the process. The subjects chosen were 10 pregnant teenagers of low income, with ages that ranged from 16 to 19 years old and who were attended in a basic health unit in Macapá, in the State of Amapá. The results led to the conclusion that it is necessary to improve sexual education within a socioeconomic perspective, not only in the schools, but also through integration with the public health units, to promote helpful environments for the teenagers to obtain information about sexuality.

Key words: adolescence, pregnancy, sexuality and public health. 
"reduzir a gravidez a apenas um conjunto de sintomas orgânicos ou a dificuldades emocionais (...)é empobrecer todo o processo e perder a oportunidade de trazer seu significado à tona para o sujeito e poder implicá-lo no processo."

BARKER; CASTRO
Tratar da gravidez na adolescência é lidar com um acontecimento complexo, tendo em vista que implica o envolvimento de vários fatores de natureza social, econômica, psicológica e fisiológica. Daí vem a importância de recorrermos a distintas áreas do conhecimento para estabelecermos uma visão menos fragmentada de um fenômeno que cresce anualmente em todo o mundo e chamarmos a atenção de pais, de profissionais que trabalham direta ou indiretamente com adolescentes e de governantes, e que se torna, assim, uma preocupação que pode ser inserida no âmbito da saúde pública. (Belo; Silva, 2004; Silva; Tonete, 2006).

Essa inserção evoca possibilidades de análise que correm o risco de formar posicionamentos extremos, que transitam de uma situação existencial desastrosa, ou mesmo patológica, até uma vertente idealizada que apregoa a supremacia do desejo de ser mãe como fonte principal de realização pessoal. Dessa forma, as preocupações legítimas com as vidas das jovens e de seus filhos podem acabar se transformando em um "campo de batalha" teórico, que pouco lhes trazem em termos de ações afirmativas. Para evitarmos, então, reforçar uma ou outra perspectiva, não ignoraremos pontos de vista distintos, pois estes podem agregar aspectos importantes para melhor compreensão da gravidez durante a adolescência.

Assim, temos as questões de ordem fisiológica, que ressaltam o aumento da mortalidade materna em função de abortos mal executados ou de complicações no parto, e o aumento da mortalidade infantil, tendo em vista os nascimentos prematuros. Descreve-se, também, que a faixa etária ideal para a mulher ter filhos varia entre os vinte e os trinta anos de idade, pois, durante a adolescência, o aparelho reprodutor da jovem ainda não está totalmente desenvolvido para gerar um bebê.

Até dois anos após a primeira menstruação, muitas adolescentes ainda não têm o tamanho ideal da bacia ou mesmo a altura adulta, e isso pode certamente trazer complicações no período de gestação. Além do mais, a ocorrência de uma gravidez em uma adolescente que mal começou a sair da infância pode significar, também, várias dificuldades de ordem emocional, cujos efeitos serão marcantes por toda sua vida. (Madeira,1997).

As constatações mencionadas acima devem ser consideradas relevantes para se lidar com a gravidez na adolescência e, como bem destacam Barker e Castro (2002), são indispensáveis quando essa gravidez acontece em uma idade muito precoce, pois realmente inspira maiores cuidados não apenas daqueles que trabalham na área da saúde mas também de familiares e educadores, a fim de que possa ser dado um suporte adequado à jovem e ao bebê durante todo o processo de gestação. Entretanto, ainda no mesmo texto, as autoras ressaltam que

"reduzir a gravidez a apenas um conjunto de sintomas orgânicos ou a dificuldades emocionais (...) é empobrecer todo o processo e perder a oportunidade de trazer seu significado à tona para o sujeito e poder implicá-lo no processo." (Barker; Castro, 2002, p. 81).

Dentro dessa mesma visão, Heilborn etal. (2002) comentam que transformar a gravidez na adolescência em uma problemática que carrega, invariavelmente, várias formas de sofrimento é simplificar a questão e defini-la como uma resposta homogênea para todos os jovens pais e mães que atravessam essa etapa. É preciso, então, contextualizar o fenômeno a partir dos próprios sujeitos, situando-os, principalmente, em suas origens socioeconômicas, para que seja possível determinar suas especificidades.

Em função disso, percebe-se a necessidade de se tratar as questões subjetivas vivenciadas durante uma gravidez na fase da adolescência. Portanto, iniciamos com um breve panorama 
teórico sobre sexualidade, adolescência e instituições de saúde para, em seguida, nos voltarmos para as questões metodológicas da pesquisa que realizamos. Esse percurso visa não apenas ao conhecimento de como as adolescentes experienciam a gravidez, mas também procura saber quais foram suas reações face à descoberta de que seriam mães e como pretendiam enfrentar uma nova realidade que causa mudanças em suas vidas.

\section{Sexualidade, adolescência e cultura}

Em uma entrevista cuja temática eram os encaminhamentos das relações homossexuais no Ocidente, a partir de fatores sociais, políticos e históricos, Michel Foucault (1982) ressalta questões interessantes sobre a forma como os relacionamentos heterossexuais se organizaram, e traça linhas que podem ser úteis para pensarmos a constituição da sexualidade atualmente.

Confirmando seu ponto de vista através de obras literárias, Foucault destaca que, a partir da Idade Média, a heterossexualidade passa a se assentar sobre dois eixos: o do amor cortês, em que a mulher é o objeto da sedução masculina, e o do ato sexual propriamente dito. Dentre essas duas vertentes, é justamente a corte que irá se tornar um valor cultural bastante difundido até bem recentemente, transformando-se na principal referência a reger as relações heterossexuais. A homossexualidade, por sua vez, dada a interdição pelo cristianismo, não pôde participar do sistema de corte, pois inexistiam elementos culturais que o sustentassem. Dessa forma, a expressão da sexualidade recaiu sobre os encontros amorosos enquanto atos físicos, consumados, muitas vezes, de maneira rápida e furtiva, a fim de que pudesse ser mantido o caráter de ocultação, tendo em vista as punições através do aprisionamento ou mesmo da morte.
Nas últimas décadas, porém, esse perfil sofreu algumas mudanças que trouxeram diferentes formas de se estabelecer os relacionamentos. As relações entre as pessoas passaram a se constituir por meio de maior prevalência do que cada parceiro espera do outro em termos de satisfação individual, sem que seja necessário, pelo menos no caso heterossexual, o aval de instituições como a família e a religião.

"Eu arriscaria a seguinte hipótese: em uma civilização na qual, durante séculos, se considerou que a essência da relação entre duas pessoas residiria no fato de saber se uma das duas partes cederia ou não à outra, (...), toda a audácia e a manipulação que provaram as partes em questão sempre visaram à submissão do parceiro com a finalidade de deitar-se com ele. Hoje, quando os encontros sexuais têm se tornado extremamente fáceis e numerosos, como é o caso dos encontros homossexuais, as complicações acontecem apenas depois do ato. (...) Uma vez consumado o ato sexual, pergunta-se, então, ao parceiro: "Qual é mesmo seu nome?". (Foucault, 1982, p.12)

Isso certamente trouxe ganhos para todos em termos de liberdade sexual ou, como diz Foucault, de "intensificação do ato sexual", e promoveu diferentes possibilidades de experimentação, especialmente para as mulheres. Mas, infelizmente, essa facilidade para manter relações sexuais com vários parceiros ao longo da vida vem sendo vinculada, também, a uma crescente falta de limites, que está se constituindo em um fator paradigmático do sujeito contemporâneo.

Para o psicanalista Charles Melman (2003), a filosofia moral atual reza "que cada ser humano deveria encontrar em seu meio com o que se satisfazer, plenamente" (p. 31), independentemente de qualquer responsabilidade para com o outro. Dentro desse contexto, o sexo passou a ser exibido
As relações entre as pessoas passaram a se constituir por meio de maior prevalência do que cada parceiro espera do outro em termos de satisfação individual, sem que seja necessário, pelo menos no caso heterossexual, o aval de instituições como a família e a religião. 
sem pudores através da mídia, convertendose numa simples necessidade que deve ser suprida sem inibições, sem vínculos, e inserindo-se como mais um item de uma longa cadeia de prazeres variados que encontramos pelo caminho, tais como a compra de novos aparelhos eletrônicos, de roupas da moda e de carros, dentre outros.

A forma como as relações se estabelecem entre as pessoas é passível de modificações profundas ao longo do tempo. Essa característica mutável da nossa existência reafirma a influência constante da História e da cultura no comportamento humano. E, como seres históricos e culturais, não podemos nos colocar fora desses âmbitos, sob pena de nos submetermos a princípios imutáveis e criarmos barreiras intransponíveis de preconceitos. A partir desse viés, então, como pensar a adolescência atualmente? Como pensar a adolescência para além das concepções estereotipadas que lhe servem de referência?

Inicialmente através do discurso biomédico e depois da Psicologia, a adolescência foi transformada em uma fase do desenvolvimento humano cujas disfunções de ordem emocional e biológica são tomadas como fatos universais, e, por conta disso, costumam excluir os condicionantes sociais, históricos e culturais. Tais noções se difundiram e passaram a ser aceitas como verdades sobre o que é ser adolescente.

Assim, além de todos os transtornos próprios da adolescência, quando ainda ocorre uma gravidez, os problemas se tornam praticamente insolúveis. A inadequação física para procriar, típica do discurso biomédico, cedeu lugar, nos anos de 1970, ao discurso da Psicologia, que apregoava a imaturidade emocional das adolescentes para serem mães. A partir dos anos 80 e 90, tais visões são conjugadas e reforçadas por um discurso social também fatalista, que verificava o aumento da delinqüência, da evasão escolar, da pobreza, etc. (Heibornet al., 2002).
Como destaca Ozella (2002) de maneira crítica, esse "estado de ser adolescente", reforçado por visões naturalistas, é formado, basicamente, pelos seguintes "sintomas":

"rebeldia, desequilíbrios e instabilidades, lutos e crises de identidade, instabilidade de afetos, busca de si mesmo, tendência grupal, necessidade de fantasiar, crise religiosas, flutuações de humor e contradições sucessivas." (Ozella, 2002, p. 19).

O "mito da invencibilidade" também se insere nessa "síndrome da adolescência". Em uma perspectiva médico-biológica como a de Straub (2005), o foco da gravidez na adolescência é dirigido para as possibilidades de adoecimento. Segundo o autor, como as atividades sexuais estão ocorrendo cada vez mais cedo, a gravidez precoce é apenas uma das conseqüências problemáticas para a vida de um adolescente.

De acordo com dados relativos aos adolescentes norte-americanos, obtidos no ano 2000, há uma grande incidência entre os jovens de doenças sexualmente transmissíveis, tais como sífilis, gonorréia, herpes genital, clamídia e AIDS, decorrentes do sexo sem proteção. Isso é justificado por Straub através do "mito da invencibilidade", isto é, a crença, muitas vezes fantasiosa, de que nada poderá acontecer de errado (gravidez, doenças, acidentes, etc.).

Como destacam Vitalle e Amancio (2001), tal mito parece ter uma parcela de responsabilidade pelo uso inadequado de contraceptivos entre os adolescentes, pois estes não acreditam que seja possível engravidar, tendo em vista que as relações costumam ocorrer de forma pouco freqüente e inesperada. Essas constatações, independentemente do ponto de vista em que são explicadas, trazem um aspecto factual inegável: as informações sobre anticoncepcionais não garantem sua utilização. Belo e Silva (2004) também corroboram essa dissociação na pesquisa que realizaram, e 
observam que o conhecimento sobre a camisinha cresceu muito nos últimos anos em virtude das campanhas publicitárias de prevenção ao vírus da AIDS, especialmente com a sua divulgação pela televisão, que, de acordo com os autores, é o meio de comunicação mais utilizado pelas jovens mães pesquisadas. Portanto, a questão de saber sobre contraceptivos não deve ser tomada de maneira única e inequívoca, pois o acesso a um determinado conhecimento bem como a sua aplicação estão estreitamente vinculados às condições subjetivas e socioeconômicas daqueles que são alvo desse saber.

E é através de tais condicionantes que emerge um aspecto importante da questão: a grande relevância que a gravidez pode assumir na vida de muitas adolescentes. Especialmente para garotas de baixa renda e com pouca escolaridade, que não dispõem de facilidades de "acesso a outros bens sociais, como educação, trabalho, remuneração e prestígio" (Villela, Doreto, 2006, p. 2469), a gravidez se torna uma maneira factível de forjar uma valorização pessoal em um meio que tem muito pouco a oferecer.

Além disso, Dadoorian (2003) nos chama a atenção para o fato de que essa modificação de valor social entre jovens pobres através da gravidez decorre da manutenção de uma divisão de papéis vinculada, ainda, a um modelo patriarcal, que determina a posição feminina como necessariamente constituída em função de atribuições domésticas, dentre elas, a da maternidade. O mesmo não ocorre nas camadas mais abastadas da população, pois a mulher tem sua identidade constituída também por meio de uma profissão.

Para podermos, então, abordar de maneira mais aprofundada as repercussões de uma gravidez na adolescência, bem como de todos os aspectos que a circundam - como o uso de contraceptivos, a aceitação ou não da família, a permanência na escola etc. -, temos que detectar a que padrões culturais essas jovens e seus parceiros estão submetidos e quais os papéis sexuais que desempenham, a fim de permitir que eles próprios construam os referenciais mais próximos da realidade em que vivem.

\section{A gravidez na adolescência e as instituições de saúde}

Um fator que merece destaque para a discussão sobre a gravidez na adolescência é o despreparo dos serviços de saúde pública que visam ao planejamento familiar no Brasil, pois não existem políticas voltadas para a população que permitam um fácil acesso dos adolescentes aos serviços de saúde, o que dificulta suas buscas tanto para a orientação quanto para o recebimento de métodos contraceptivos. O adolescente necessita de um serviço de saúde com atendimento diferenciado, que possa levar em consideração seus referenciais subjetivos, mas que seja capaz, também, de oferecer respostas claras para suas dúvidas.

No Brasil, os primeiros serviços específicos para os adolescentes surgiram, na década de 1970, no Rio de Janeiro e em São Paulo, e difundiram-se, de forma ampla, por mais de dez anos, por ambos os Estados. O Programa de Saúde do Adolescente, em São Paulo, foi reconhecido pela Organização Mundial da Saúde / Organização Pan-Americana da Saúde, e considerado o centro colaborador da América Latina.

Os esforços despendidos na implementação do Programa pelos Estados do Sudeste levaram à criação da Associação Brasileira de Adolescência e à oficialização do Programa de Saúde do Adolescente (PROSAD) em âmbito nacional, promovido pelo Ministério da Saúde. As áreas prioritárias trabalhadas pelo PROSAD são: crescimento e desenvolvimento, sexualidade, saúde mental, saúde reprodutiva, saúde escolar, saúde bucal, prevenção de acidentes, violência e família. 
Um marco legal de referência para as políticas dirigidas aos adolescentes é o Estatuto da Criança e do Adolescente, consubstanciado na lei no 8.069, de 13/07/ 1993. Esse Estatuto estabelece direitos e direciona as questões que envolvem a Justiça, além de instituir, entre os principais mecanismos de execução das políticas em relação às crianças e aos adolescentes, a instalação de conselhos de defesa e conselhos tutelares (Borges, 1999). No Estado do Amapá, o programa PROSAD foi implantado na década de 1990, e ainda hoje caminha com muitas dificuldades. Atualmente, inexiste, em nível estadual e municipal, um serviço público de saúde específico e estruturado para a atenção e a saúde do adolescente. Essa clientela é atendida com a demanda geral dos serviços, o que gera inibições no adolescente que procura informações sobre sua saúde.

No ano de 2002, o Governo do Amapá implementou o projeto de saúde denominado Prevenção da Gravidez na Adolescência. Dada a complexa realidade do Estado, faz-se necessária uma reestruturação dos serviços de saúde pública referentes ao planejamento familiar e à saúde do adolescente, que integram as dimensões interdisciplinares ao trabalho, através da participação de psicólogos, assistentes sociais, enfermeiros e outros profissionais da mesma área.

\section{Os caminhos metodológicos}

Optamos por uma abordagem qualitativa para este estudo, tendo em vista as seguintes características: a capacidade de propiciar melhor interação entre pesquisador e pesquisados, sua flexibilidade na aplicação e, segundo Minayo (1998), a preocupação com a realidade trabalhada quando se torna impossível a quantificação. Dentro dessas condições, o pesquisador pode alargar o seu conhecimento e a sua experiência acerca do assunto pesquisado, aprofundando-se nele e contextualizando-o dentro de uma realidade específica. Obtivemos, assim, os subsídios necessários para o conhecimento desse importante fenômeno - de repercussões nos âmbitos individual, familiar e social -, que é uma gravidez na vida de uma adolescente.

O local escolhido para a pesquisa foi uma unidade básica de saúde na cidade de Macapá, capital do Estado do Amapá, pois essa unidade atende um grande número de adolescentes grávidas que fazem os exames pré-natais, e também por já ter desenvolvido um programa denominado Saúde do Adolescente, um serviço de referência para o Estado na década de 1990 e que, infelizmente, não mais existe.

Seguindo a faixa etária estipulada pela Organização Mundial da Saúde (OMS), os sujeitos que participaram do estudo foram dez adolescentes grávidas de baixa renda, com idades entre 16 e 19 anos. A escolha por jovens de baixo poder aquisitivo se deu em função do público em relação ao qual se direcionam os atendimentos da unidade de saúde onde a pesquisa foi realizada.

Para a coleta de dados, utilizamo-nos da entrevista semi-estruturada individual, com perguntas abertas. De acordo com Minayo (1998), a entrevista deve ser o facilitador da entrada, da ampliação e do aprofundamento da comunicação. Nesse mesmo sentido, Triviños (1995) comenta que a entrevista semiestruturada é, em geral, aquela que parte de certos questionamentos básicos, apoiados em teorias e hipóteses referentes à pesquisa, e que, em seguida, oferecem um vasto campo de interrogativas, fruto de novas hipóteses que vão surgindo à medida que se recebem as respostas do informante.

As informações que obtivemos, após a leitura de todo o material, levaram-nos à construção de sentidos da realidade vivenciada pelas adolescentes e permitiram-nos ultrapassar a fase de interpretação dos dados para, finalmente, ensejar o cotejamento dos 
resultados conseguidos com as teorias já desenvolvidas sobre o tema.

A forma como abordamos a questão da gravidez para as adolescentes se deu a partir da subdivisão em dois níveis: o nível intrapessoal da adolescente, que contempla o ciclo vital, a sexualidade, a maternidade e os projetos de vida, e o nível interpessoal da adolescente, que consiste na relação com o pai de seu bebê e com a família de origem. Tendo em vista a finalidade deste artigo, comentaremos apenas os resultados relativos ao nível intrapessoal da adolescente.

\section{Vivências de uma nova realidade}

A gravidez na adolescência traz consigo peculiaridades interessantes sob o ponto de vista da pesquisa psicossocial, em que permeiam a subjetividade da adolescente e os interesses das famílias dos envolvidos. Engravidar ainda adolescente mobiliza, portanto, questões basilares relativas às instituições da nossa sociedade e da formação dos indivíduos, tais como os sistemas de saúde pública, a escola e, certamente, a própria família. Daí as dificuldades por que perpassa a análise de tal fenômeno.

A percepção das adolescentes relacionadas aos ciclos vitais, compreendidos entre a infância e a idade adulta, veio comprovar a existência de grandes mudanças nessas etapas a partir da descoberta da gravidez. Há uma nova vivência a ser experimentada, vinculada, principalmente, às pressões sociais e às cobranças internas, que impõem comportamentos de maturidade e configuram uma passagem direta ao "mundo dos adultos". "Agora, por exemplo, eu estou vendo muita diferença na minha adolescência...eu não esperava isso, mas aconteceu, vamos levar pra frente. Ser criança é ser inocente e não saber muito bem das coisas...é está partindo para adolescência. Ser adulto é ter responsabilidade." (A., 18 anos, 60 mês de gravidez, primeiro filho).

De um modo geral, a infância foi considerada pelas jovens como uma etapa positiva, tal como revelado em suas falas: "é maravilhoso", "a gente brinca e se diverte", "não tem preocupação com nada". Na relação com a família, percebe-se a alegria pelo menor controle exercido pelos pais durante a infância, ao mesmo tempo em que reforçam a situação de dependência relativa ao pai e à mãe, pois "a gente não sabe o que faz" e "é bom ter a mãe por perto". A infância se caracterizaria, então, como o período em que os pais é que precisam ser responsáveis.

Em última instância, na percepção de nossas entrevistadas, a adolescência é considerada uma fase marcada por descobertas e por diversões, ainda que seja necessário "ter juízo". Não obstante, um acontecimento como a gravidez precoce tem o poder de mudar o rumo dos acontecimentos, levando a novos desenvolvimentos na vida da adolescente.

A idade adulta se estabelece para elas como uma etapa em que "já se sabe de tudo", "já se sabe um pouco mais das coisas". Ser adulto implica, também, independência financeira, e torna obrigatório o trabalho "para sustentar os filhos". Outra questão relevante é que a gravidez as insere, de maneira obrigatória, em experiências adultas, o que implica um amadurecimento bem mais antecipado do que o que teriam se não estivessem esperando um filho. E essa perspectiva advém não apenas delas próprias, mas de pressões dos familiares, pois agora existe uma criança para ser cuidada e educada.

"Acho que com esse filho que agora eu peguei, eu acho que estou entrando na fase adulta, né?...tendo que mudar certas coisas...porque muitas coisas que eu fazia eu deixei de fazer, e agora com esse negócio de pré- natal eu mudei muitas coisas...". (G., 17 anos, 4o mês de gravidez, primeiro filho).
Engravidar ainda adolescente mobiliza, portanto, questões basilares relativas às instituições da nossa sociedade e da formação dos indivíduos, tais como os sistemas de saúde pública, a escola e, certamente, a própria familia. 
Com relação à questão da sexualidade e à utilização de métodos anticoncepcionais, as entrevistadas ressaltaram a importância do conhecimento sobre o tema, principalmente para prevenir doenças sexualmente transmissíveis, como a AIDS, por exemplo. Mas, como afirma uma das adolescentes, "prevenir a gravidez também é importante". Assim, ficou clara uma certa preocupação, nos discursos das jovens, com a gravidez, ainda que estivesse caracterizada a inadequação do uso de métodos preventivos. Somente num dos casos pesquisados, em que havia um relacionamento estável com o parceiro, o desejo de engravidar foi explicitado.

Os dados constatados acima corroboram as considerações de Belo e Silva (2004) sobre o conhecimento de métodos anticoncepcionais aliados à sua não utilização. Em nossa pesquisa, essa situação tornou-se mais ostensiva em face da situação de pobreza, que impõe dificuldades até mesmo para a obtenção de uma simples consulta médica em uma unidade pública de saúde. Dessa forma, a camisinha se torna o método preferencial, pois "para usar comprimido tem que passar a noite toda aqui no posto, na fila", comenta uma das adolescentes. Ainda assim, sua utilização é inconstante, levando, muitas vezes, à gravidez.

Porém, a gravidez, muitas vezes considerada "não planejada" é, na verdade, uma resposta da adolescente a um desejo de ter filhos, e a realização de tal desejo pode ser atribuída à mudança de status dentro da família ou do meio social em que vive. Como já comentamos através de Villela e Doreto (2006), para meninas de baixo poder econômico, que não possuem muitos dos referenciais imaginários próprios das jovens da classe média - tais como estudar em uma boa universidade, ter empregos que lhe tragam muitas satisfações materiais etc. -, a gravidez se torna o foco de muitas expectativas e sonhos.

O aspecto comentado acima aparece de maneira interessante na ambigüidade da seguinte fala, cujo saber sobre a possibilidade de engravidar se acha atrelado a um pretenso desconhecimento a respeito de sua ocorrência na realidade:

"Sempre soube que em uma relação sexual eu podia engravidar. (...) Recebi informações sobre anticoncepcionais, na escola, em casa, na televisão. O único método que usei foi a camisinha. (...) Eu não esperava [engravidar]. Quase que eu tenho um troço" (A., 18 anos, 6o mês de gravidez, primeiro filho).

Para as adolescentes, a descoberta da gravidez produz um impacto no momento da confirmação do diagnóstico (diagrama de significações 1). Esse impacto gera um sentimento inicial de desespero. $\mathrm{Na}$ tentativa de resolver o problema, o aborto acaba surgindo como uma opção, principalmente quando a adolescente não possui uma rede de apoio para lhe dar suporte. Quando o aborto é mal sucedido, a adolescente passa a carregar um sentimento de culpa por ter tentado tirar a vida de filho. Além do mais, permanece o temor de que a criança apresente uma má formação ao nascer.

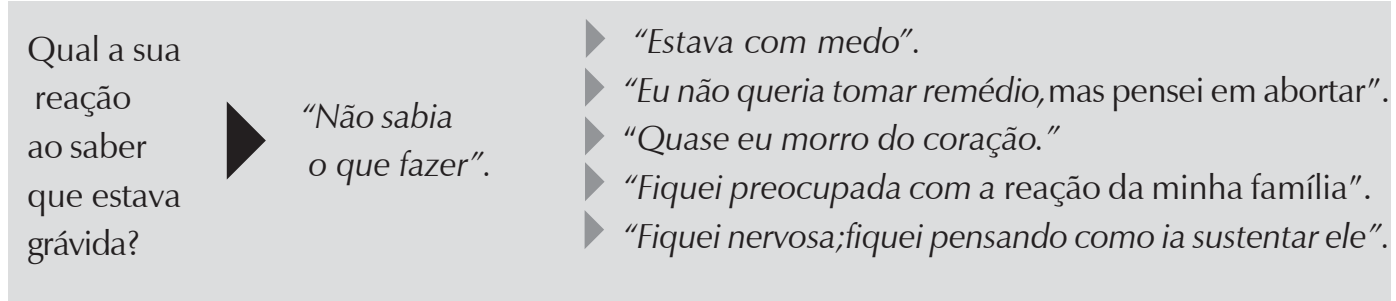

Figura1 - Diagrama de significações sobre a reação das adolescentes após a descoberta da gravidez. 
Daí se percebe a experiência de ser mãe se constituindo e da maternidade considerada a realização de um sonho que traz desde a infância: ter um filho e poder cuidá-lo para que seja feliz. Dessa forma, passado o primeiro momento de angústia, vem a fase de aceitação da gravidez e do planejamento futuro. O filho assume um significado muito grande para a adolescente (diagrama de significações 2), e torna-se um novo objetivo em suas vidas. "Agora eu tenho um filho para lutar por ele". E esse novo objetivo se configura, pois, em uma forma de encarar o mundo e as pessoas, de enfrentar as problemáticas que advêm de uma gravidez precoce.

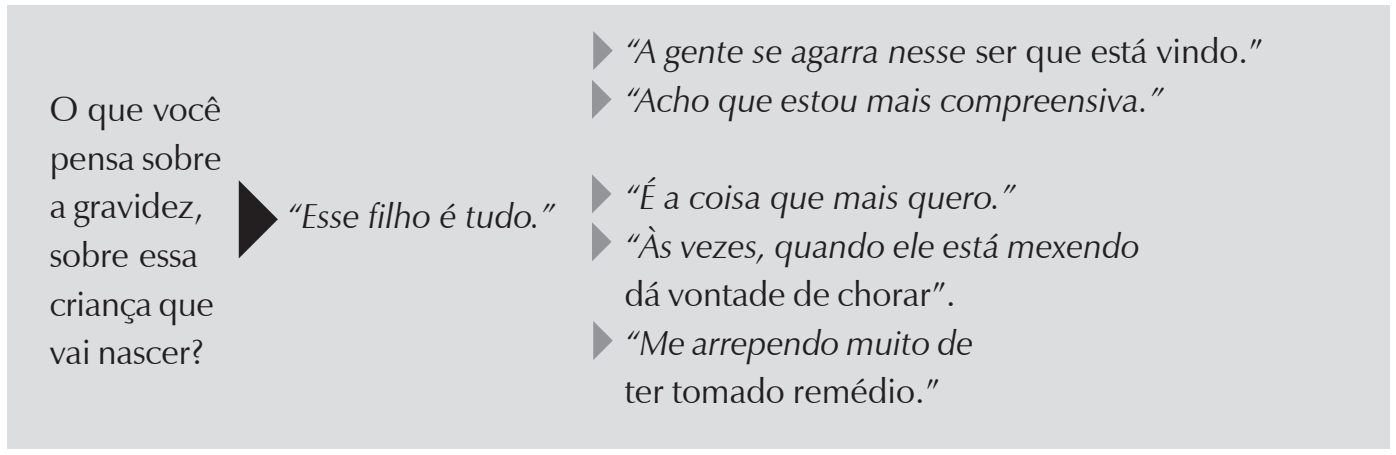

Diagrama de significações 2 - Sentidos da gravidez.

Em um estudo sobre o projeto de vida de adolescentes grávidas e pobres, Menezes (1993) comenta que, além de verificar que ser mãe na adolescência altera as potencialidades do desenvolvimento pessoal e social das jovens, com o abandono da escola e do trabalho, a situação de pobreza faz com que a questão adquira uma outra dimensão, e gera conseqüências bem mais graves.

Entretanto, como bem destacam Heilborn et al. (2002), as adolescentes das classes populares que engravidam já têm uma carreira escolar bastante irregular, e isso não é resultado de uma relação direta com a ocorrência da maternidade. Assim, a probabilidade de essas jovens saírem do estado de pobreza, com ou sem filhos, é uma perspectiva bastante remota, pois a repetição desse ciclo perverso de manutenção da baixa renda familiar costuma se perpetuar através das gerações e desconsiderar, dessa forma, as possíveis potencialidades que essas jovens poderiam desenvolver.

Todos os sonhos passam a direcionar-se, então, para a criação do filho, e o sentimento mais comum surgido em suas falas foi o de que querem fazer todo o possível para que a criança estude em uma boa escola, tenha muito amor e carinho, e que nada lhe falte.

"Agora eu tenho que me esforçar bastante para dar o que eu puder pra ele, né? Não deixar faltar nada, terminar meus estudos, não pra mim, mas pra ele, tenho que dedicar toda minha vida pra ele agora." (A., 18 anos, 6o mês de gravidez, primeiro filho).

"Meu projeto é comprar uma casa, [mas] meu bebê aparece em primeiro lugar em meus planos, eu vejo ele estudando, eu vejo ele bem de saúde, se Deus quiser. Já para os próximos dez anos, eu não sei nem o que falar...eu só sei que quero que o meu filho estude." (G., 17 anos, 4으ês de gravidez, primeiro filho).

\section{Considerações finais}

Para que a gravidez transcorra com tranqüilidade, faz-se necessário que a adolescente seja acompanhada pelos serviços de saúde, através de atendimentos especializados, com profissionais 
capacitados na área. Assim, ela reunirá condições para ter um período de gestação saudável e um parto humanizado. Portanto, tem que se adequar a assistência dada às adolescentes de maneira específica, diferenciando-a daquela prestada às gestantes adultas.

Tal diferenciação, no entanto, não deve advir das concepções rígidas sobre o que é ser adolescente, ainda que essas concepções influenciem a visão daqueles que trabalham com esse público. As idéias desses profissionais sobre a adolescência, comentadas por Ozella (2002), trazem as seguintes marcas: o mundo adulto é almejado, mas não o seguem como modelo; são alienados quanto às questões políticas e sociais, tanto em nível pessoal como global; não gostam de estudar; são muito consumistas e sempre têm problemas relacionais, o que os faz se sentirem muito sozinhos.

Assim, a necessidade de se diferenciar o atendimento aos adolescentes reflete-se, na verdade, em propostas que minimizem situações de conflito e sofrimento em relação ao início da vida sexual. São "possíveis ações educativas dentro das unidades de saúde, desde que não reproduzam o discurso moral e inibidor contrário à educação libertadora" (BARROS, 2002, p.49), isto é, devem ser criadas condições para que os próprios adolescentes exerçam a sexualidade de maneira a não comprometer a sua saúde e a de seus parceiros e abrir espaço para encontrar soluções frente aos preconceitos e crenças que se formam sobre o sexo. Essas ações, ainda que implementadas em um ambiente necessariamente multidisciplinar, são um campo privilegiado para o trabalho dos psicólogos.

Por fim, queremos ressaltar que esta pesquisa não se restringiu apenas à investigação dos fatos. Tivemos também o interesse de levar recomendações aos gestores do Programa de Saúde da Adolescência, no âmbito estadual e municipal, objetivando a melhoria na qualidade do atendimento aos adolescentes nas unidades públicas de saúde do Estado do Amapá. A prioridade é conferida às adolescentes muito jovens, de forma que possam usufruir de uma boa estrutura relativa ao atendimento preventivo bem como gozar de uma assistência pré-natal de qualidade.

Em função do exposto, propõe-se que seja implementado o Programa de Saúde do Adolescente nas Secretarias do Estado e nos Municípios de Estado do Amapá; devem-se formar parcerias entre o Programa de Saúde do Adolescente e o Projeto de Gravidez na Adolescência, da Secretaria do Estado de Saúde do Amapá (SESA), para ações conjuntas; criar um centro de referência para o atendimento especializado em adolescentes dentro do Município de Macapá que esteja em sintonia com os principais programas de saúde; inserir, na rotina desse centro de referência, um espaço permanente para o atendimento familiar; capacitar equipe multidisciplinar e disponibilizar métodos de contracepção para os adolescentes, para que eles possam escolher aqueles que thes sejam mais convenientes, com critérios médicos de elegibilidade estabelecidos pela Organização Mundial da Saúde (OMS).

A vinculação da área de saúde com a educação, explicitada antes, pode se dar, também, através da articulação entre os Programas de Saúde do Adolescente do Estado e dos Municípios com a Secretaria Estadual de Educação e dos Municípios, objetivando a capacitação e a atualização de professores da rede pública em educação sexual, com foco nos aspectos subjetivos e nas condições socioeconômicas dos adolescentes beneficiados, e não na mera reprodução antiquada de um discurso biológico.

Com as propostas consideradas acima, acreditamos que seja possível, de maneira significativa, reduzir as angústias de tantas adolescentes, principalmente as de baixa renda, que dispõem de pouco apoio no que se refere ao acompanhamento de uma gravidez. 


\begin{tabular}{|r|}
$\begin{array}{r}\text { Florinaldo Carreteiro Pantoja } \\
\text { Mestre em Psicologia pela Universidade de Fortaleza - UNIFOR } \\
\text { Júlia Sursis Nobre Ferro Bucher } \\
\text { Professora do Curso de Mestrado em Psicologia da Universidade de Fortaleza - UNIFOR } \\
\text { Doutora pela Universidade Católica de Louvain - Bélgica } \\
\text { Cristiane Holanda Queiroz } \\
\text { Mestre em Psicologia pela Universidade de Fortaleza - UNIFOR } \\
\text { Av. Washington Soares, 1321, CEP.: 60811-341. Fortaleza - CE. fone: (85) 3477-3219 } \\
\text { E-mail: agathon@fortalnet.com.br }\end{array}$ \\
\end{tabular}

BARKER, S. L.; CASTRO, D. M. F. de. Gravidez na adolescência: dando sentido ao acontecimento. In: CONTINI, Maria de Lourdes J.; KOLLER, Sílvia Helena (org.). Adolescência e Psicologia: concepções, práticas e reflexões críticas. Brasília: Conselho Federal de Psicologia, 2002. p.78- 84 .

BARROS, M. N. dos S. Saúde sexual e reprodutiva. In: CONTINI, Maria de Lourdes J.; KOLLER, Sílvia Helena (Org.). Adolescência e Psicologia:concepções, práticas e reflexões críticas. Brasília: Conselho Federal de Psicologia, 2002. p. 46-54.

BELO, M. A. V.; SILVA, J. L. P. E. Conhecimento, atitude e prática sobre métodos anticoncepcionais entre adolescentes gestantes. Revista de Saúde Pública, v.38, n.4, p.479-487, 2004.

BORGES, R. Gravidez na adolescência e reconhecimento social: estudo de caso de adolescentes grávidas no bairro Saco Grande / Monte Verde, zona urbana de Florianópolis, SC. Dissertação de mestrado - Universidade Federal de Santa Catarina, Florianópolis, 1999.

DADOORIAN, D. Gravidez na adolescência: um novo olhar. Psicologia: Ciência e Profissão, v.21, n.3, p. 84 - 91, 2003.

FOUCAULT, M. (1982). Escolha sexual, ato sexual. (on line). Available: < http://www.unb.br/fe/tef/filoesco/foucault/ > Acesso em: 05 outubro 2006

HEILBORN, M. L.; SALEM, T.; ROHDEN, F.; BRANDÃO, E.; KNAUTH, D.; VÍCTORA, C.; AQUINO, E.; MCCALLUM, C.; BOZON, M. Aproximações socioantropológicas sobre a gravidez na adolescência. Horizontes Antropológicos, v.8, n.17, p.13 - 45, 2002.

MADEIRA, A. M. F. M. Maternidade na adolescência: uma análise à luz do discurso médico. Enfermagem em Revista, v.3, n.6, p.21-30, 1997.
MELMAN, C. O homem sem gravidade - gozar a qualquer preço; entrevistas por Jean-Pierre Lebrun. Rio de Janeiro: Companhia de Freud, 2003.

MENEZES, I. C. B. B. de. A gravidez e o projeto de vida: uma análise das adolescentes grávidas das camadas populares. Tese de doutorado - Pontifícia Universidade Católica de São Paulo, São Paulo, 1993.

MINAYO, M. C. de S. O desafio do conhecimento: pesquisa qualitativa em saúde. São Paulo- Rio de Janeiro: Hucitec- Abrasco, 1998.

OZELLA, S. Adolescência: uma perspectiva crítica. In: CONTINI, Maria de Lourdes J.; KOLLER, Sílvia Helena (Org.). Adolescência e Psicologia:concepções, práticas e reflexões críticas. Brasília: Conselho Federal de Psicologia, 2002. p. 16 - 24.

SILVA, L.; TONETE, V. L. P. A gravidez na adolescência sob a perspectiva dos familiares: compartilhando projetos de vida e cuidado. Revista Latino-americana de Enfermagem,v. 14, n. 2, p.199-206, 2006.

STRAUB, R. O. A Psicologia da saúde ao longo do curso da vida. In: STRAUB, R.O. Psicologia da Saúde. Porto Alegre: Artmed, 2005. p. 535-570.

TRIVIÑOS, A. N. S. Introdução à pesquisa em ciências sociais: a pesquisa qualitativa em Educação. São Paulo: Ed. Atlas S.A., 1995.

VILLELA, W. V.; DORETO, D. T. Sobre a experiência sexual dos jovens. Cadernos de Saúde Pública. v. 22, n.11, p.2467 - 2472, 2006.

VITALLE, M. S. de S.; AMANCIO, O. M. S. (2001). Gravidez na adolescência (on line). Available: < http:// www.brazilpednews.org.br/set2001/bnpar101.htm > Acesso em: 30 janeiro 2007. 